\title{
Effect of ladle thermal state on the LF endpoint temperature of molten
}

\section{steel}

\author{
Yifei Huang ${ }^{1, a}$, Wei Xiong1, b ${ }^{1}$ Zhiyong Fan ${ }^{1, c}$ \\ ${ }^{1}$ Key Laboratory for Ferrous Metallurgy and Resources Utilization of Ministry of Education, Wuhan \\ University of Science and Technology, Wuhan 430081, China \\ a380082757@qq.com, bxiongwei@wust.edu.cn, c452833101@qq.com
}

Keywords: LF refining; ladle thermal state; endpoint temperature; mathematical model Abstract. Molten steel temperature is a key parameter related to LF refining, and it has an important influence on steel quality and casting. Aimed at a steel ladle with capacity of 300 tons, a heat transfer model was developed. Ladle wall and bottom lining temperature distribution curve was obtained. The factors influencing LF endpoint molten steel temperature was analyzed. The results show that LF endpoint molten steel temperature would reduce $8-11^{\circ} \mathrm{C}$ if ladle repair time extends 30 minutes. $\mathrm{LF}$ endpoint molten steel temperature would raise $4^{\circ} \mathrm{C}$ if ladle is baked for 30 minutes. The rate decreases with the extension of baking time. The temperature would increase $1.5^{\circ} \mathrm{C}$ if baking gas temperature increases $200^{\circ} \mathrm{C}$. The temperature would reduce $1.0^{\circ} \mathrm{C}$ if awaiting time increases 5 minutes.

\section{Introduction}

Ladle is an intermediary vessel between the steel-making and pouring. Ladle thermal state in the process of production and turnover especially in tapping has a direct impact on molten steel temperature of tapping and transport [1,2]. And affect casting quality and productivity. [3,4]. Effect of different ladle condition heat transfer process on molten steel temperature was studied. Control the steel-making process and reasonable procedures for continuous casting plays an important role in guiding. The factors affecting the thermal state of ladle include: repairing time, baking time, baking gas temperature, awaiting time. [5,6]. During ladle turnover process, the emptied ladle is cleaned and repaired to prepare for next tapping. The time spent during these processes is defined as repairing time. The time spent for baking ladle is defined as baking time. The time spent between baking ladle and tapping is defined as awaiting time.

Aimed at a steel ladle with capacity of 300 tons, a ladle heat transfer model was developed in this paper. he factors influencing LF endpoint molten steel temperature was analyzed.

\section{Mathematical Model}

A ladle is same as a conical barrel in steelmaking plant. In order to use cylindrical coordinates in the model, a ladle is regard as a column. Assuming,

(1) Thickness of each layer material remains the same in ladle

(2) Ladle inner lining height remains the same

(3) Molten steel height in ladle remains the same with same mass of molten steel

Through the above assumptions, molten steel height could be determined by the following equation. 


$$
\begin{aligned}
& V=\frac{W_{\text {iron }}}{\rho_{\text {iron }}} . \\
& V=\frac{1}{12} \pi h_{\text {iron }}\left(d_{1}^{2}+d_{1} d_{2}+d_{2}^{2}\right) . \\
& d_{2}=d_{1}+2 h_{\text {iron }} \operatorname{tg} \theta .
\end{aligned}
$$

where $V$ is volume of molten steel, $\mathrm{m}^{3} . W_{\text {iron }}$ is mass of molten steel, t. $\rho_{\text {iron }}$ is density of molten steel, $\mathrm{t} \cdot \mathrm{m}^{-3} \cdot d_{1}, d_{2}$ is diameter of ladle bottom and molten steel surface, $\mathrm{m} . h_{\text {iron }}$ is molten steel height, m.

Molten steel height is obtained, Eq. 4 is used to calculated internal diameter of ladle $\mathrm{d}_{0}$.

$$
d_{0}=\sqrt{\frac{4 V}{\pi h_{\mathrm{iron}}}} .
$$

Set base steel capacity is 300 tons. Simplified internal diameter of ladle is $3.8628 \mathrm{~m}$ and outer diameter is $4.4248 \mathrm{~m}$. Sketch of cylindrical ladle model is shown in Fig. 1.

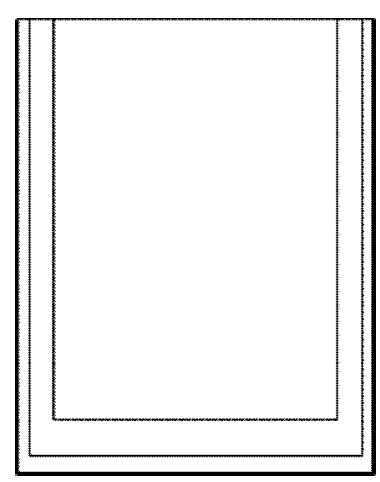

Fig. 1 Ladle model

Wall and bottom of ladle and internal temperature can be obtained by solving the heat equation. Owing to wall height is greater than wall thickness, ladle wall is assumed as infinitely long cylinder, only radial heat flux are considered. Owing to ladle diameter is greater than ladle bottom thickness, ladle bottom is assumed as thin circular plate, only axial heat flux are considered. Owing to ladle cover diameter is greater than cover thickness, ladle cover is assumed as thin circular plate, only axial heat flux are considered.

Ladle wall heat conduction equation is,

$$
\frac{\partial T_{\text {wall }}}{\partial \tau}=\frac{1}{\rho_{\text {wall }} \cdot C_{p w a l l}(T)}\left[\frac{1}{r} \frac{\partial}{\partial r}\left(\lambda_{\text {wall }}(T) \cdot r \frac{\partial T_{\text {wall }}}{\partial r}\right)\right] .
$$

Boundary conditions are,

$$
\left.\begin{array}{l}
r=r_{\text {wall-in }}, q_{\text {wall-in }}=q_{1} \\
r=r_{\text {wall-out }}, q_{\text {wall-out }}=\alpha_{\text {wall-env }}\left(T_{(\mathrm{r} \text { wall-out })}-T_{\text {env }}\right) \\
\tau=0, T_{\text {wall }}=T_{\text {wall }}(r)
\end{array}\right\} .
$$

Ladle bottom heat conduction equation is, 


$$
\frac{\partial T_{b o t}}{\partial \tau}=\frac{1}{\rho_{b o t} C_{p b o t}(T)}\left[\frac{\partial}{\partial z}\left(\lambda_{b o t}(T) \frac{\partial T_{b o t}}{\partial z}\right)\right]
$$

Boundary conditions are,

$$
\left.\begin{array}{l}
z=\mathrm{z}_{\text {bot-in }}, q_{\text {bot-in }}=q_{2} \\
z=z_{\text {bot-out }}, q_{\text {bot-out }}=\alpha_{\text {bot-env }}\left(T_{(\text {zbot-out })}-T_{\text {env }}\right) \\
\tau=0, T_{b o t}=T_{b o t}(z)
\end{array}\right\} .
$$

Ladle cover heat conduction equation is,

$$
\frac{\partial T_{\mathrm{cov}}}{\partial \tau}=\frac{1}{\rho_{\mathrm{cov}} C_{p \mathrm{cov}}(T)}\left[\frac{\partial}{\partial z}\left(\lambda_{\mathrm{cov}}(T) \frac{\partial T_{\mathrm{cov}}}{\partial z}\right)\right]
$$

Boundary conditions are,

$$
\left.\begin{array}{l}
z=z_{\text {cov-in }}, q_{\text {cov-in }}=q_{3} \\
z=z_{\text {cov-out }}, q_{\text {cov-out }}=\alpha_{\text {cov-env }}\left(T_{(\mathrm{cov}-o u t)}-T_{\text {env }}\right) \\
\tau=0, T_{\text {cov }}=T_{\text {cov }}(z)
\end{array}\right\} .
$$

\section{Results and Discussions}

Different process of the ladle bottom and wall lining temperature curve is shown in Fig.2. Ladle inner surface temperature is very high and radiation is very strong in repairing time after casting. However, inner surface temperature drops rapidly. Inner surface temperature drops to $850^{\circ} \mathrm{C}$ after 60 minutes, and ladle bottom temperature is higher. Inner layer of refractory material temperatures up to $1000^{\circ} \mathrm{C}$ after baking, and it is benefit for reducing lining heat in next tapping. Because tapping time is short, only inner surface temperature of working layer that close to molten steel raise. In process of transport, refining and casting after tapping, permanent layer and heat insulation layer temperature and heat gradually increase, but increase gradually reduced.
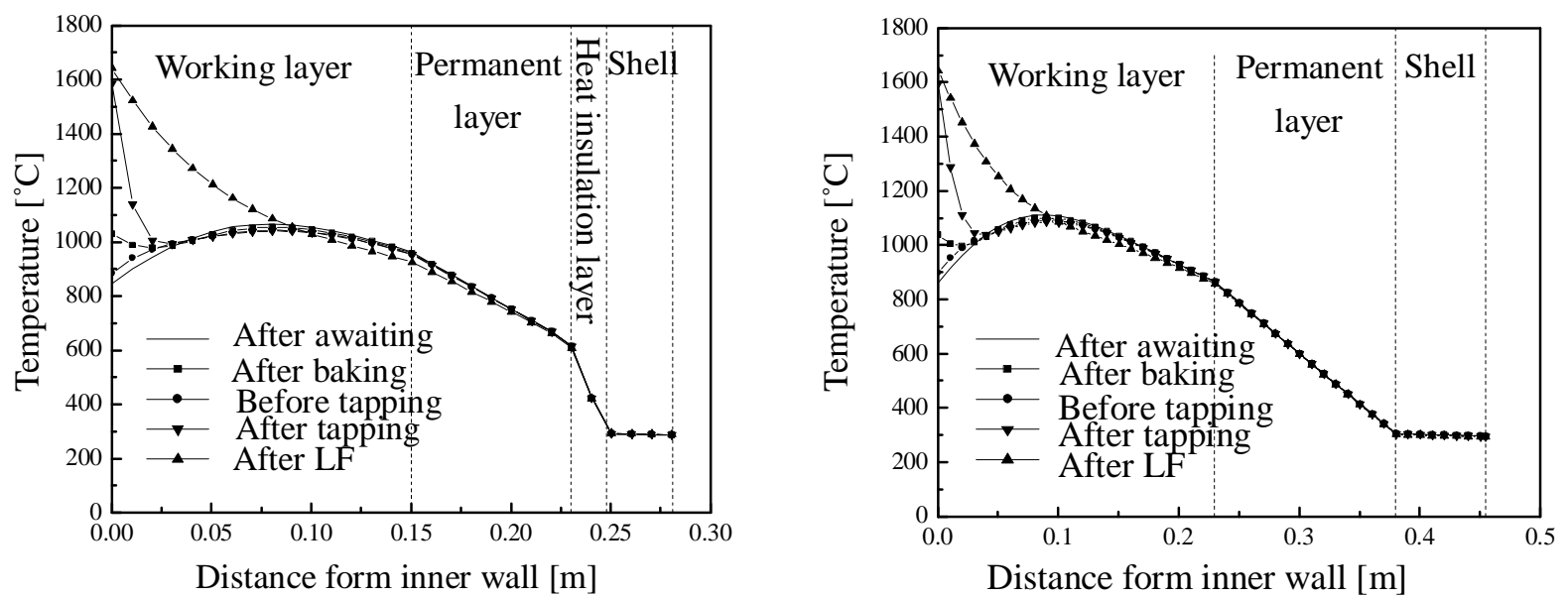

Fig.2 Different process of ladle lining the wall and bottom of the curves

Ladle will go through repairing, baking and awaiting after casting. Effect of ladle repairing time before baking on molten steel temperature is shown in Fig.3. Effect of repair time on molten steel temperature drop is obvious. $\mathrm{LF}$ molten steel temperature drops $8-11^{\circ} \mathrm{C}$ when repairing time extends 
30 minutes.

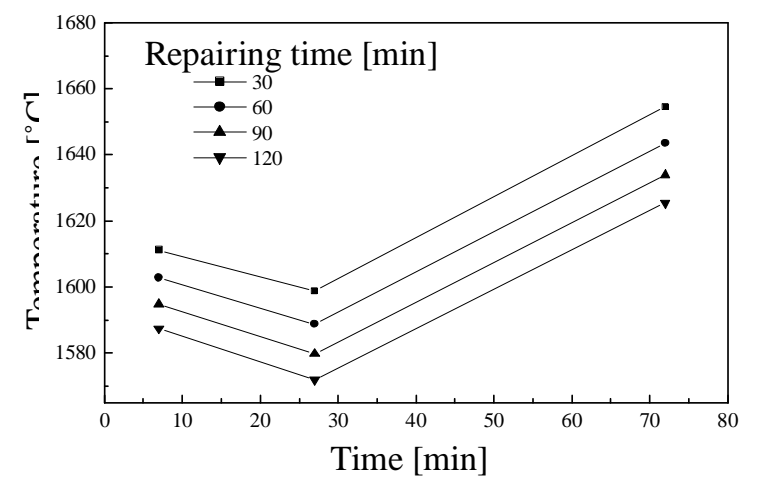

Fig.3 Effect of repairing time on temperature

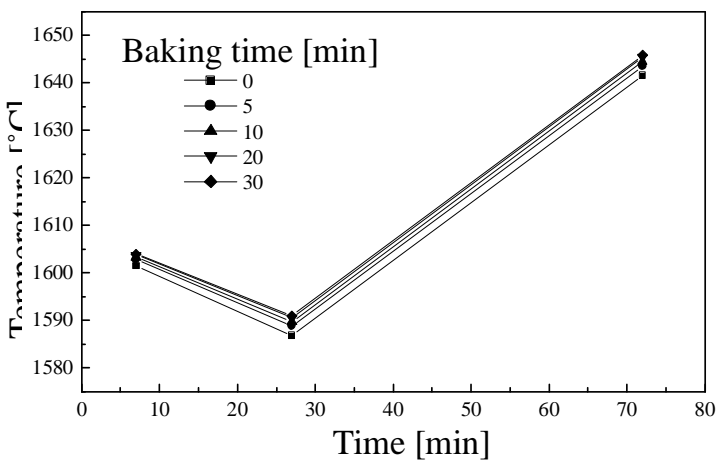

Fig.4 Effect of baking time on temperature

In order to reduce ladle lining heat absorption, ladle should be baked before tapping. Effect of baking time on molten steel temperature is shown in Fig.4. Rapid baking 30 minutes ladle molten steel temperature than without baking after LF refining 4 degrees higher. Ladle baking is necessary before tapping. But with the extension of baking time, effect of molten steel temperature drop reduces. $\mathrm{LF}$ molten steel temperature raise $2.9^{\circ} \mathrm{C}$ of baking 10 minutes and molten steel temperature raise $1.0^{\circ} \mathrm{C}$ of baking another 10 minutes, and molten steel temperature raise $0.4^{\circ} \mathrm{C}$ of baking next 10 minutes. This means without change baking time, accelerating the ladle turnover, reduced awaiting time is more important. If gas temperature is higher, effect of molten steel temperature is more obviously with baking time increase.

\section{Conclusions}

(1) Only inner surface temperature of working layer that close to molten steel raise during tapping. In process of transport, refining and casting after tapping, permanent layer and heat insulation layer temperature and heat gradually increase.

(2) Effect of repair time after casting on molten steel temperature drop is obvious. LF molten steel temperature drops $8-11^{\circ} \mathrm{C}$ when repairing time extends 30 minutes.

(3) Ladle baking before tapping is necessary. But effect of slow the molten steel temperature drop reduced if bake more than 20 minutes. Accelerate ladle turnaround, reduce awaiting time is more important if baking time is determined.

\section{References}

[1] D. F. He, A. J. Xu and P. F. Wu: Journal of University of Science and Technology Beijing, Vol. 33 (2011), p. 110

[2] S. Sonoda, N. Murata and H. Hino: ISIJ International, Vol. 52 (2012), p. 1086

[3] Y. F. Chen and Y. Wang: China Science \& Technology Panorama Magazine, Vol. 12 (2015), p. 59

[4] X. D. Wu, Q. Liu and A.J. Xu: Journal of University of Science and Technology Beijing, Vol. 23 (2001), p. 418

[5] J.K. Brimacombe and I.V. Samarasekera: Iron \& Steelmaker, Vol. 21 (1994), p. 29

[6] F. Yuan, D. F. He and A. J. Xu: Shandong Metallurgical, Vol. 6 (2012), p. 36 
